\title{
Using futures methods to create transformative spaces: visions of a good Anthropocene in southern Africa
}

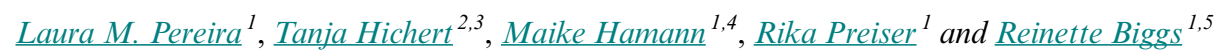

\begin{abstract}
The unique challenges posed by the Anthropocene require creative ways of engaging with the future and bringing about transformative change. Envisioning positive futures is a first step in creating a shared understanding and commitment that enables radical transformations toward sustainability in a world defined by complexity, diversity, and uncertainty. However, to create a transformative space in which truly unknowable futures can be explored, new experimental approaches are needed that go beyond merely extrapolating from the present into archetypal scenarios of the future. Here, we present a process of creative visioning where participatory methods and tools from the field of futures studies were combined in a novel way to create and facilitate a transformative space, with the aim of generating positive narrative visions for southern Africa. We convened a diverse group of participants in a workshop designed to develop radically different scenarios of good Anthropocenes, based on existing "seeds" of the future in the present. These seeds are innovative initiatives, practices, and ideas that are present in the world today, but are not currently widespread or dominant. As a result of a carefully facilitated process that encouraged a multiplicity of perspectives, creative immersion, and grappling with deeply held assumptions, four radical visions for southern Africa were produced. Although these futures are highly innovative and exploratory, they still link back to current real-world initiatives and contexts. The key learning that arose from this experience was the importance of the imagination for transformative thinking, the need to capitalize on diversity to push boundaries, and finally, the importance of creating a space that enables participants to engage with emotions, beliefs, and complexity. This method of engagement with the future has the potential to create transformative spaces that inspire and empower people to act toward positive Anthropocene visions despite the complexity of the sustainability challenge.
\end{abstract}

Key Words: Anthropocene; futures; imagination; scenarios; southern Africa; transformative spaces; transformations

\section{INTRODUCTION}

The Anthropocene is a new epoch in which humanity has become a dominant global force reshaping the geological dynamics of Earth (Crutzen 2002, Steffen et al. 2015). It brings with it new and diverse challenges, such as an increasing disconnect between people and nature, widening inequalities, degradation of essential ecosystem services, and potential planetary tipping points (Millennium Ecosystem Assessment 2005, Barnosky et al. 2012). On the other hand, it presents many opportunities for improving human well-being, through technological advances and an increased understanding of systemic interdependencies and risks. In southern Africa, the Anthropocene manifests in intractable, interconnected social-ecological challenges such as poverty, inequality, high levels of urbanization, food insecurity, as well as marginalization and exploitation within the global economy. Although many of these issues constrain and impact negatively on human well-being across the region, some of the Anthropocene-related changes taking place also create significant opportunities for creating better futures.

It is increasingly recognized that navigating the challenges posed by the Anthropocene requires more than isolated and piecemeal solutions to specific social, ecological, or technical problems; it requires large, systemic transformations in social-ecological systems (SES) for the world to transition onto a more sustainable, long-term future trajectory (Bennett et al. 2016, McPhearson et al. 2016). Currently the sustainable development goals (SDGs) are used to guide interventions aimed at bringing about more sustainable and just transitions by 2030 (United Nations 2015). However, much of our current thinking about the future is constrained by the extrapolation of aspirations that are valued in the present, and may not be radical enough to effect deep systemic transformations. History has shown that such transformations are essentially impossible to predict; there are just too many uncertainties and complexities to consider (Bland and Westlake 2013). The Industrial Revolution and European Enlightenment could not have been imagined by the citizens of Medieval Europe, but they nevertheless came into being by building on existing ideas and technologies of the Medieval Period, and led to a deep systemic transformation in how society was organized and functioned (see Polanyi 1944, Arthur 2011). Neo-colonialism, globalization, and the age of the internet are similarly transforming how humans interact with each other and with the planet today (Harari 2016), setting the stage for the development of new institutions, practices, worldviews, and values.

Considering that systemic transitions can take 40 or more years to develop (Arthur 2011, Nye 2014), radically alternative, novel development pathways are required to transition current systems (energy, food, transport etc.) to more sustainable trajectories of production and consumption. Although there is an acknowledgement that the future could look radically different from anything predicted by the present (J. Voros 2015, unpublished manuscript), most scientific methods for engaging with the future involve statistical forecasting, trend analysis, and models that project from past experience. Moreover, the notion of the future is often conceptualized and presented as an extrapolation or linear unfolding of events where novelty is assumed to be the logical outcome of the chronological order of time (Sornette and Cauwels 2015). Developing alternative visions of the future

\footnotetext{
${ }^{1}$ Centre for Complex Systems in Transition, Stellenbosch University, South Africa, ${ }^{2}$ Hichert and Associates Pty Ltd, ${ }^{3}$ Foresight for Development, ${ }^{4}$ The Natural Capital Project, Institute on the Environment, University of Minnesota, St. Paul, MN, USA, ${ }^{5}$ Stockholm Resilience Centre, Stockholm University, Sweden
} 
requires novel concepts and tools for envisaging and realizing desirable worlds (See Bennett et al. 2016). Such methods contribute to the creation of "transformative spaces," carefully facilitated processes that are designed to enable transformative change.

The field of futures studies, and more recently the discipline of anticipation, provide a new set of tools and approaches for reconceptualizing the future more creatively. Scenario planning is the most widely known or commonly used method for envisioning alternative futures, but a variety of tools and approaches exist (Bishop et al. 2007). Other new methods include exploring the complexity, chaos, and contradictions of postnormal times (Sardar and Sweeney 2016), as well as experiential scenario work (Candy and Dunagan 2017). By developing capacities to read and apply "futures literacy" (Miller et al. 2013) we gain skills and knowledge about why, when, and how to use the notion of the future appropriately (Miller et al. 2013, Poli 2015a). Futures literacy is furthermore grounded on the assumption that the nature of reality and of the future is complex (Miller 2013) and that it is possible to reconceptualize the notion of the future as being neither deterministic, nor completely open (Urry 2016). Using the future to create transformative spaces requires new methods and approaches that can deal with the complexity and immensity of Anthropocene challenges. The methods need to make provision for getting well beyond archetypal, generic narratives of the future, such as "technology will save us," or "collapse and decline" (Hunt et al. 2012). As Moore et al. (2014) point out, envisioning is one phase of a much broader transformation process, but it is often an essential first step to create the changed understanding and commitment that set the stage for bringing about radical shifts in a system.

In this paper we describe a case study where participatory future studies methods were used to create a transformative space through a process of generating positive narratives for southern African. The case study forms part of the global Seeds of Good Anthropocenes (SOGA) project (Bennett et al. 2016, Pereira et al. 2018). The SOGA project is premised on the idea that "seeds" of more positive Anthropocene futures exist in the present. These seeds are defined as innovative initiatives, practices, and ideas that are present in the world today in some form, but are not currently widespread or dominant (Bennett et al. 2016). It focuses on collecting such seeds of potential transformative change, and explores how these seeds can be used as a starting point to construct radical, but plausible, stories of the future. The project is premised on the idea that producing vivid, hopeful, bold, inspirational visions and stories of more sustainable, equitable futures can inspire us to move toward the values and ideals of a "good Anthropocene" (Bennett et al. 2016, Preiser et al. 2017).

\section{TRANSFORMATIONS AND FUTURES THINKING}

The trouble is that the unknowable future cannot be grasped from the point of view of the search for probable futures. This is because the probable depends on the already known whereas the novel arises from the previously unimaginable (Miller 2013:107).

The SOGA project is grounded in an emerging understanding of how change occurs in complex adaptive social-ecological systems (SES) and integrates two key existing frameworks: socio-technical transitions (Geels 2002), and social-ecological transformations (Olsson et al. 2006, Moore et al. 2014). Drawing on the Olsson et al. (2006) framework, the project conceptualizes change in SES as comprising three interconnected phases: preparation, navigating the transition, and consolidation. In the preparation phase, growing awareness of some systemic problem at a macro level inspires a diversity of local-scale experiments, or seeds that emerge as responses to Anthropocene challenges (Pereira et al. 2018). To become connected or organized into "proto-regimes," these experiments require a build-up of momentum (Geels 2002). The premise of the project is that compelling positive visions of the future can provide the basis for gathering momentum amongst the seeds, involving self-organization around new ideas, the creation and mobilization of networks of support, and experimentation in protected niches. When a destabilizing crisis arises, these proto-regimes provide potential "solutions" that can be adopted by decision makers in need of new strategies, leading to institutionalization (the navigation phase). In the consolidation phase, institutionalization at the meso-scale is critical for bringing about larger systemic change (Pereira et al. 2018).

Research suggests that inspirational stories and visions can be key components of transformations to sustainability (Moore et al. 2014, Bai et al. 2016, Milkoreit 2016). Hence, facilitated visioning processes can help shape the future by changing how people understand the world, what they expect from it, and what they deem possible (van der Helm 2009, Wiek and Iwaniec 2014). This changed understanding influences behavior, the types of experiments that people may undertake, and what solutions are adopted in times of crisis. According to Evans (2017), a critical component of the visioning process is the creation of narratives or "myths." He argues that in this time of global crisis and transition, it is only by finding new myths, those that speak to us of renewal and restoration, that we will be able to navigate our way to a better future. Stories, rather than facts and pie-charts, have the power to animate us and bring us together to change the world (Evans 2017). The Nigerian author Ben Okri similarly writes about the importance of harnessing the power of the imagination to deal with the uncertainty of the future:

\begin{abstract}
How do we awaken imagination? How do we awaken vision? One of the ways, passed down to us with cunning simplicity by our ancestors is storytelling ... when we listen to stories, our future takes clearer shape. ... The things the heart knows shine a greater light than the things the head knows (Okri 2015:21).
\end{abstract}

The discipline of anticipation distinguishes between planning for the future, preparing for the future, and using novel futures to discover new ways to make sense of the emergent present and take advantage of the unknowable future (Poli 2015b). It is the latter objective, that of imagining the unknowable future, enabling us to reassess actions and choices in the present critically, that was the focus of the southern African visioning workshop discussed in this paper. Our emphasis was not to test present assumptions against some predicted future, nor about optimization (planning for some goal) or contingency (preparing for some threat), but rather about novelty: using the future to anticipate probable futures through the creation of a transformative space.

This conceptual underpinning of the future highlights how the SOGA project aims to imagine futures that are at once truly novel 
trajectories of future developments, as well as concrete enough to inspire practical action by being grounded in existing seeds. These seeds are alternative ways of thinking or doing, technologies and institutions that exist in an experimental form, but are not dominant features of today's world, and that someone in the world believes will contribute to a more desirable future (Bennett et al. 2016). The SOGA project is deliberately experimenting with a range of different scenario methods to develop a set of approaches that are better able to imagine and anticipate emergent change, as well as engage and inspire key actors (Pereira et al. 2018).

In Africa, where futures are often predicated upon western ideals of development, making explicit the relevance of local cultures and the importance of the past for navigating the future is critical. An oral storytelling tradition persists on the continent, and for the southern African SOGA process, it was thus imperative that the aspect of narrative and myth was included in our visioning exercise. Africa is a potent place for stories:

\begin{abstract}
Africa breathes stories. In Africa everything is a story, everything is a repository of stories. Spiders, the wind, a leaf, a tree, the moon, silence, a glance, a mysterious old man, an owl at midnight, a sign, a white stone on a branch, a single yellow bird of omen, an inexplicable death, an unprompted laughter, an egg by the river, are all impregnated with stories. In Africa things are stories, they store stories, and they yield stories at the right moment of dreaming, when we are open to the secret of objects and moods. (Okri, as cited in Okorafor 2009:276)
\end{abstract}

The visioning process we designed in southern Africa aimed to draw on this ripe story-telling culture to enable a radical departure from conventional scenario narratives.

\section{METHODOLOGICAL APPROACH}

To create a transformative space where participants could engage thoughtfully with the future and draw on their inherent capacity for storytelling to unearth the rich narratives of the southern African region, we developed an adapted "Mānoa mash-up" method, which we piloted in a carefully facilitated process at an exploratory Anthropocene Visioning Workshop for southern Africa. This "Mānoa mash-up" combines an adaptation of the Mānoa approach for generating scenarios (Schultz 2015) with the Three Horizons Framework (Curry 2015, Sharpe et al. 2016).

\section{Mānoa mash-up method: facilitating participatory scenario building}

The original Mānoa scenario building method was developed in 1992 for the Hawaii Research Center for Futures Studies (Bishop et al. 2007, Schultz 2015) and is distinct from the Mānoa method described by Dator (2009). Its underlying rationale is based on working with emerging issues, or weak signals, to explore their primary and long-range impacts, and the possible interconnections and outcomes of those impacts (Schultz 2015). It is a method that maximizes difference from the present, in contrast to the more well-known "double uncertainty matrix" approach associated with traditional scenario planning that focuses on key unknowns. The Mānoa scenario method is designed to generate divergent, surprising scenarios that evolve from changes and impacts proliferating over several decades, and is best suited for creative, innovative, and transformational thinking (Schultz 2015).
We adapted the Mānoa method by using selected seeds initiatives from the SOGA project database as a starting point for generating scenarios, instead of using weak signals as per the traditional Mānoa method. By using actual existing initiatives as starting points for the scenario development, we aimed to anchor our creative and transformational visions of the future in current realworld initiatives and contexts. To develop our visions of alternative futures, we combined the adapted Mānoa scenario building method with the Three Horizons framework, which is a graphical approach developed to explore the change in importance of issues over time, and connect the future to the present (Curry 2015). It is considered an adaptable futures tool, and is often used as an intuitive, accessible introduction to futures thinking, as well as to make sense of emerging changes. When used in conjunction with scenarios, it helps to provide internal structure to scenario narratives because it depicts overlapping and often competing timelines of unfolding change. In particular, the Three Horizons approach has been applied to identify key ideas and actions that facilitate transitions from one way of doing things (business as usual) to more transformative patterns (Sharpe et al. 2016). By combining the adapted Mānoa method based on seeds with the Three Horizons framework, our mash-up approach struck a balance between not just exploring creative, radical visions of the future, but also linking those futures to real-world projects and initiatives in the present, and considering the possible pathways and points of intervention that link the present to our future visions.

\section{The Anthropocene Visioning Workshop}

We piloted the Mānoa mash-up method at a three-day workshop in Cape Town, South Africa, in November 2016. A carefully selected group of 23 key thinkers, artists, scientists, and change makers, as well as seven facilitators with diverse backgrounds, including ecology, geography, philosophy, and futures studies, were convened to produce visions of good Anthropocenes in southern Africa.

\section{Participant selection and preparation}

Participants were chosen to represent a diversity of professional backgrounds and interests: scientists ranged from economists, political scientists, and cultural theorists to climate change scientists and environmental scientists; artists were represented by dancers, landscape and visual artists; and a variety of social entrepreneurs were present, including a renewable energy innovator and a chef. The participants embodied a diversity of cultural backgrounds, ages, genders, and experiences (See Table 1). All of the participants were recognized as social innovators who have agency and influence in an array of social networks and institutions (See Biggs et al. 2015). The initial list of potential participants was sourced from the professional network of the author group, the main selection criteria being a demonstrable interest in sustainability issues and the human-environment interface, as well as a reputation for open-mindedness and the ability to work in groups. Further invitees were identified through snowball sampling, until enough participants were secured to form four groups of appropriate size (five to six people each).

For each of the four scenario groups, we aimed to include representatives of two of the three seed projects used within that group. In addition to the two seeds representatives we included at least one scientist, one artist, and one practitioner in each group. 
Practitioners were people involved in nongovernmental organizations, with previous government experience or large international institutions like the United Nations Environment Program. Each group comprised a mix of very different stakeholders, each with distinct perspectives and values. Our aim in doing so was to maximize diversity within groups, to create fertile ground for discussion and, ultimately, rich, diverse narratives of the future.

Table 1. Demographic breakdown of workshop participants

\begin{tabular}{llc}
\hline \hline Demographic & Category & $\begin{array}{c}\text { Number of } \\
\text { participants }\end{array}$ \\
\hline Gender & Female & 13 \\
& Male & 10 \\
Ethnicity & Black African & 7 \\
& African American & 1 \\
& White South African & 6 \\
& White non-South & 3 \\
& African & \\
& Colored/Cape Malay & 4 \\
Age group & Hispanic/Latino & 2 \\
& Under 25 & 1 \\
& 26-35 & 11 \\
& 36-45 & 6 \\
& 45 and over & 5 \\
\hline
\end{tabular}

In the invitation to the workshop, the background and aims of the SOGA project were explained, and participants were given an overview of the planned workshop process. However, not too much detailed information was shared, to avoid biasing the participants' views and expectations.

\section{Workshop process}

The workshop was structured into four distinct phases spread over three days. Phase 1 focused on "setting the scene" to make sure that all participants were introduced to each other through a creative process of activating conversation and interaction. The second phase was dedicated to creating "scenario skeletons," i.e., outlines of stories depicting radically alternative futures. The third phase focused on the elaboration, refinement, and exploration of those scenarios ("deep dive"). During the second and third phases, participants worked exclusively in their assigned groups. Finally, in the fourth phase, the groups creatively shared their visions of radically different futures for southern Africa with one another, and then jointly discussed their reflections, experiences, and what they had learned from the process.

Throughout the workshop, participants were encouraged to visit the "Anthropod," a separate room that was set up with a camera and interviewer who would ask participants to reflect on how they were feeling, what they were experiencing, and their overall thoughts about the process that they were undertaking. Participation in the Anthropod was voluntary, but the participants chose to use it as a means to reflect and debrief over the three days.

\section{Phase 1: Setting the scene}

On the first day, before embarking on the scenario building exercise, it was important to introduce participants to the concepts and challenges of the Anthropocene, have them meet each other, as well as sensitize them to the nature of shared dialogue about unknowable futures. This was done by means of an opening presentation about the Anthropocene and an overview of the SOGA project. The presentation was followed by a two-hour interactive Platform for Research in Art, Culture, \& Theory in Society (PRACTIS) session on art, imagination, and futures run by a workshop participant, Dr Rael Salley. In this session, participants met each other and were led through exercises that sensitized them to their inherent assumptions in how they viewed the world. This phase was important for initiating group bonding and setting the context and tone for the vision development exercises in the following phases.

\section{Phase 2: Constructing scenario skeletons}

After the initial introductory sessions, the participants were allocated to their groups. Each group was also allotted a group facilitator from the SOGA project team. Participants worked in the same groups for phases 2 and 3 , which fostered group identity and allowed for deep dialogue.

Each group received short descriptions of three different preidentified seed projects that formed the starting points for developing scenario skeletons. In each group, two of the group members represented two of the seeds, adding depth of knowledge and expertise to the discussions in each group. Two of the seeds in each group were based on southern African projects (and were generally the ones represented by individuals), while the third seed represented a novel and emerging global technology (See Table 2). The three seeds in each group were purposefully chosen to be distinct and dissimilar from each other to encourage diversification of ideas.

Futures Wheels: To get to scenario skeletons, participants first had to consider their assigned seeds, and imagine each of them in a future mature condition, i.e., as a mainstream "new normal" rather than a fringe activity. The impacts and implications of the seeds as a mature, mainstream condition were explored using the Futures Wheel method (Glenn 2009). Futures Wheels (Figs. 1 and 2) is a graphic method, similar to a collectively brainstormed mind-map that identifies direct and indirect future consequences or impacts of a particular change or development. For each seed, participants had to consider the primary, secondary, and tertiary levels of impacts of the seed in its imagined mature condition. To think through the various potential impacts in a structured manner, participants were encouraged to apply the STEEPV analysis, which explicitly considers Social, Technological, Economic, Environmental, Political, and Value impacts (Schultz 2015). In addition, participants were encouraged to use the VERGE framework for exploring changes in the world (Lum 2015). VERGE prompts participants to consider different domains of human experience: How would this seed in its mature condition influence the way we define things, relate to one another, connect to each other (and the environment), create, consume, or destroy? With the help of these tools, participants were able to map out the consequences of their mature seeds, and push potential future changes to their extreme conclusions.

Mapping connections and Cross-impact matrices: Once the Future Wheels for each seed were completed, the groups spent time discussing and mapping out the connections and interactions between different impacts of the three seeds. The groups were instructed to identify those impacts of the seeds in their mature conditions that they found particularly interesting, and to note 
Table 2. A list and brief description of the seed initiatives used to construct each scenario

\begin{tabular}{lll}
\hline \hline Name of Scenario & Seed Initiative & Brief Description \\
\hline Rhiz(h)ome & Tyisa Nabanye & $\begin{array}{l}\text { Tyisa Nabanye is a nonprofit organization located on the slopes of Signal Hill in Cape Town. Started in } \\
\text { August 2013, this collaboration between food security activists, neighbors, and people living on the site, aims } \\
\text { to create a space in which to explore the growing of food in an urban environment. Activities include an } \\
\text { organic vegetable garden, an indigenous nursery, a weekly market, workshops, and events that support the } \\
\text { goals of food security and employment creation. }\end{array}$ \\
& $\begin{array}{l}\text { Massive small is a global network changing systems to unleash the power of smallness in cities. It was } \\
\text { established five years ago as an independent, free thinking, open-source organization. The massive small } \\
\text { project is the work of the smart urbanism research and development collaborative, a London-based social } \\
\end{array}$ & $\begin{array}{l}\text { value business. They are creating a concise body of collective knowledge designed to change top-down } \\
\text { systems to help and inspire people and governments to work together, allowing communities to shape their } \\
\text { own environments and make towns and cities that work for the people, not against them. } \\
\text { Cryptocurrency is a digital or virtual currency that uses cryptography for security. A cryptocurrency is } \\
\text { difficult to counterfeit, and is not issued by any central authority, rendering it theoretically immune to } \\
\text { government interference or manipulation. This digital currency makes it easier to transfer funds with minimal } \\
\text { processing fees, allowing users to avoid the steep fees charged by most banks and financial institutions for }\end{array}$ \\
& wire transfers.
\end{tabular}

Radical Translocal Community Based Natural Resource Management

Reconstructed Living Lab (RLabs)

Artificial Meat

Post Exodus

Open Streets Cape Town

Knowledge Pele

Gene Editing Technologies

Demos42 Ubuntunse Future Cape Town

Slow Food Youth Network

Artificial Intelligence
CBNRM is a concept based on the ideas of community participation in the management of natural resources through democratic decentralization that leads to development and poverty alleviation, whilst also resulting in the sustainable use and conservation of natural resources. It empowers communities by providing rights over land and natural resources, building skills capacity, establishing community decision making bodies, and promoting community advocacy.

This global social enterprise was founded in 2008 and aims to reconstruct communities through training, innovation, and entrepreneurship. The main hub is located in Athlone, Cape Town. RLabs creates an environment where people are empowered to make a difference in the lives of others. Its central activities are skills and training, community development, social and disruptive innovation, mobile and internet solutions, social enterprise incubation, impact investing, and social franchising.

Artificial meat (in-vitro meat) is the idea of manufacturing meat products through tissue engineering technology, using many of the same techniques traditionally used in regenerative medicine. The first cultured beef burger patty was created in 2013 . The creation process of cultured meat includes harvesting muscle stem cells from cow neck by means of biopsy. These cells are then induced to grow into muscle tissue in a lab. In a life cycle analysis, it was calculated that in vitro meat may significantly reduce the environmental footprint of meat consumption.

OSCT is a citizen-driven initiative working toward changing how streets are used, perceived, and experienced in Cape Town. Rooted in "street action" and research, the aim is to create shared spaces that bring people together, and to challenge the paradigm of urban mobility by carrying out campaigns, temporary interventions, dialogues, and walks that raise citizen awareness, spark public debate, and ultimately drive behavior change around the role of streets in the life of the city.

Knowledge Pele is a research and development advisory firm that believes in knowledge as the foundation for development. The institution's main goal is to be the leading source of granular information about underprivileged communities, to guide the design of innovative and impactful social investments. The purpose of the company is to develop energy communities, by catalyzing structural change through businesses that generate power and knowledge.

Gene editing allows changing the DNA of any organism. More precisely, gene editing (or genome editing) is the insertion, deletion, or replacement of DNA at a specific site in the genome of an organism or cell. It is achieved using engineered nucleases, also known as molecular scissors. Until recently, this editing process was incredibly time consuming and cumbersome. In contrast, CRISPR- Cas9, a new gene editing technology that emerged in the last $\sim 5$ years, is cheap, quick, and easy to use. Given the power and potential of this new technique, researchers hope to use it to eliminate diseases, for example, or create hardier crops. Although it is clear that CRISPR has much to offer, its rapid acceleration of the gene editing field has also caused concern about the ethics and safety of its use.

Future Cape Town was founded in 2010 and has become a leading platform in Africa to inspire more liveable cities. Through their online presence, research, and multistakeholder collaborations they work toward expanding public access to urbanism in order to promote a more visionary and inclusive city. They are an independent think tank, advocating knowledge and citizen engagement to meet the challenges of a modern city. Future Cape Town is the founding partner of Our Future Cities, which also houses Future Johannesburg, Future Lagos, and Future London.

SFYN is an international network of young people working toward change in the field of food production and consumption. The network believes in the philosophy of "good, clean, and fair" food as a reaction against the upcoming fast food chains. The network unites groups of active young Slow Food members over the globe into one international network, raising awareness about food issues and providing means to take action.

Artificial Intelligence (AI) is the science of making computers perform tasks that require human intelligence. The goal of AI is to build systems that can match or exceed the cognitive capabilities of human beings across a range of domains. This holds potential to drive incredible efficiencies, increase productivity, and if AI reaches its potential, it will likely change our world in unexpected ways. AI has slowly become a major part of our world without some of us even noticing. Indeed, one of the most sophisticated pieces of specialized AI in use today is the Google Search Algorithm. 
Fig. 1. An example of a Future Wheel based on the seed "Future Cape Town" in the Demos42 Ubuntunse group.

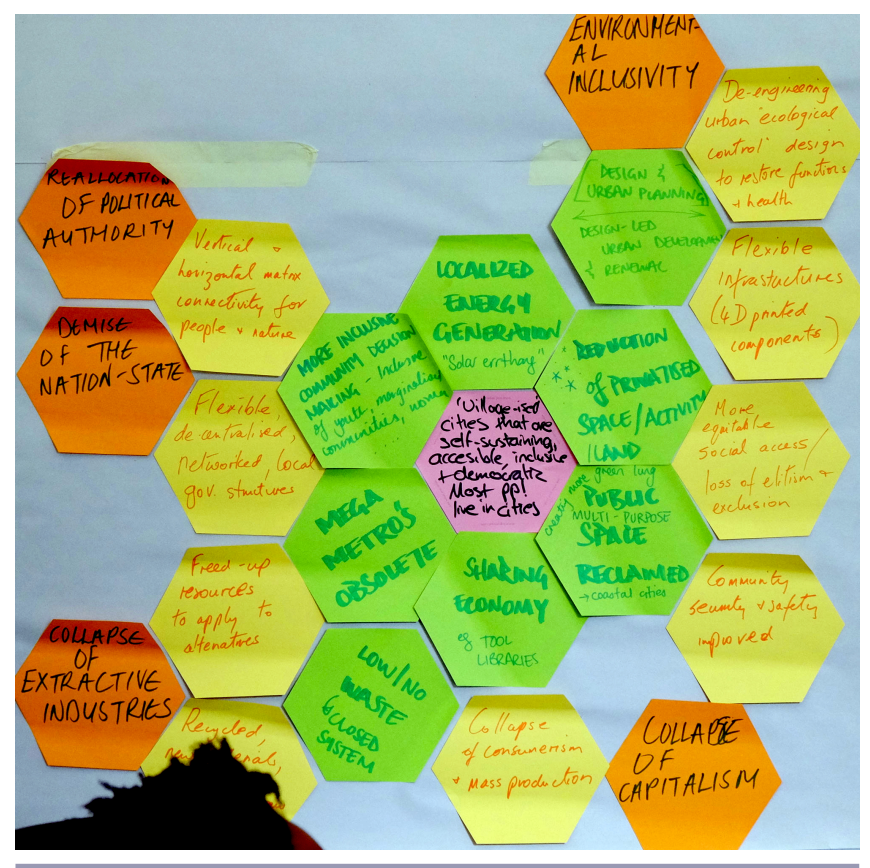

Fig. 2. An example of a Future Wheel produced in the Rhiz(h) ome group based on the "Tyisa Nabanye" seed.

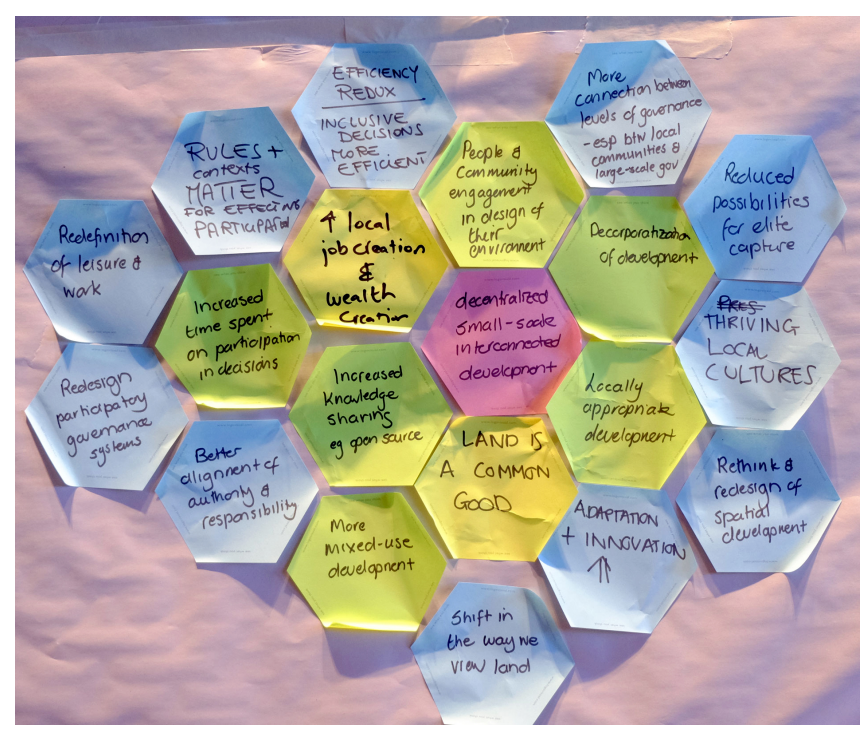

specific examples of one seed's impact supporting, amplifying, or accelerating impacts of other seeds. It was also deemed important to identify contradictions, surprising possibilities, and counterintuitive outcomes. To further deepen the participants' understanding of the potential interactions between seeds, each group also completed a cross-impact matrix to identify ways in which one seed could impact another, and vice versa (Fig. 3). This exercise further highlighted potential collisions and/or synergies between seeds using an interaction map (Fig. 4).
Fig. 3. An example of a Cross-Impact Matrix from the Rhiz(h) ome group.

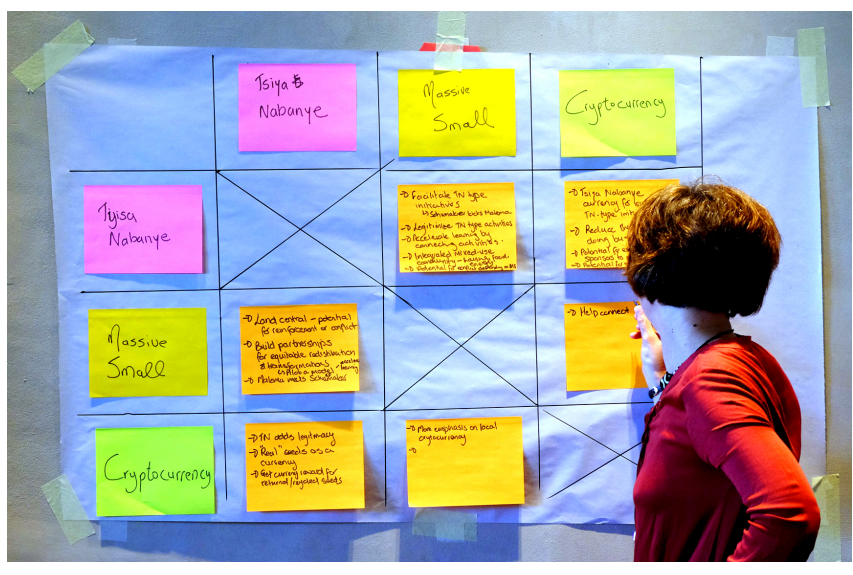

Fig. 4. An example of an interaction map combining the futures wheels with the results from the cross-impact matrix (pink squares) in the Radical Translocal group.

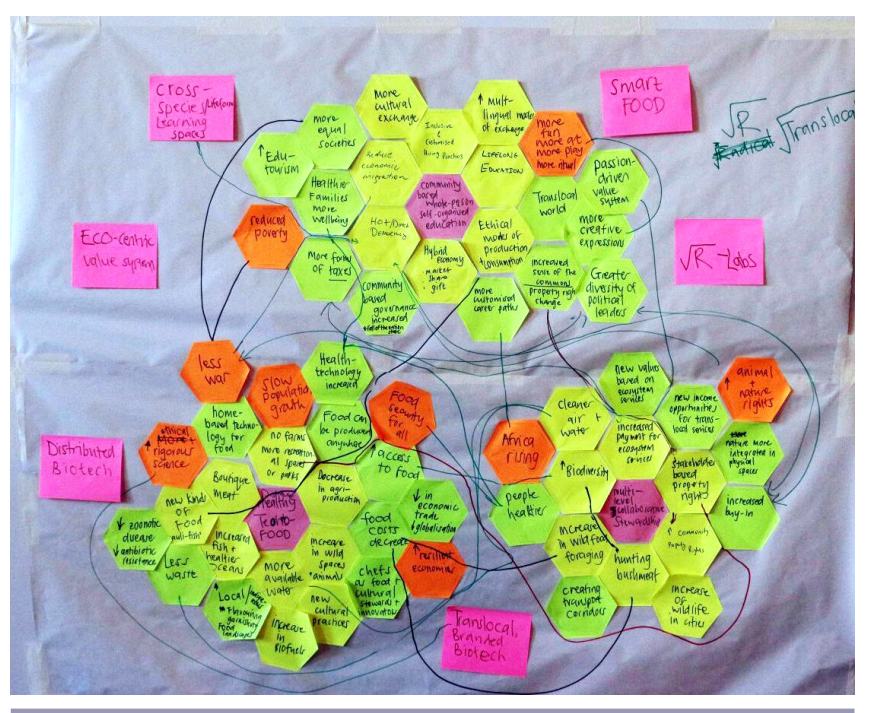

As a final step on the first day, which had involved several hours of in-depth dialogue, each group was asked to stand back, contemplate the rich material they had generated, and start looking for emerging narratives and storylines of a future vision of a good Anthropocene in southern Africa. After getting a sense of the emerging story, each group had to create one artistic image (in any medium), three fictional statistics, and a news headline representing their future vision. The groups used these to present their "scenario skeletons" to each other at the end of the day.

Phase 3: Deep Dive into scenarios

The third phase of the workshop focused on deepening and expanding on the skeleton narratives from the previous day. Groups were asked to produce bold, vivid, hopeful stories of their good Anthropocene in southern Africa. To do this, groups were 
encouraged to ensure an imaginative "stretch" of their scenario skeletons, challenge their current assumptions about present conditions continuing in a linear way into the future, combine changes or impacts between their mature seeds in a way that amplified difference from the present, and reverse constraints or threats that presently exist.

Three Horizons: To help the groups enrich their scenario narratives, and explore the pathways that could lead from the present to those envisioned futures, the groups were led through an exercise of applying the Three Horizons framework. This graphical approach allowed exploration of the transition space and pathways that could lead to the systemic changes envisioned. The future vision of each group was considered as Horizon 3, where the seeds are mainstream and large societal transformations have taken place. The goal was then to map out and connect the vision in Horizon 3 to the present in Horizon 1 by talking through systemic changes, amplifications, clashes, and potential inflection points in the Horizon 2 transition space (Fig. 5). This in turn provided additional rich material with which to embolden and embellish, but also sense-check, the developing scenarios.

Fig. 5. Three Horizons Framework from the Post Exodus group.

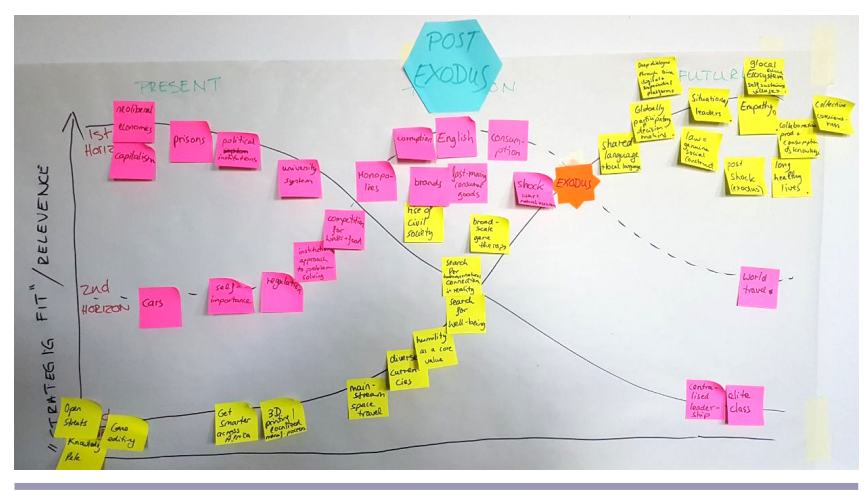

Phase 4: Artistic presentations of scenarios and sharing learning/ reflections

The third day of the workshop provided an opportunity for each group to present their scenario to the other groups, and thereafter share learnings and reflections about their experience of using the future in this process. The final part of Day 2 was allocated to the preparation of these presentations. There were no prescriptions or requirements for what these future visions should contain or how they should be presented. All the groups delivered highly creative renditions of their scenarios by using theatre, props, movement, music, costumes, and lighting to share their stories and descriptions of a good Anthropocene in southern Africa (see Fig. 6). Some groups alluded to how this future came about, while others focused on providing rich detail of how their future world worked. The four scenario narratives Rhiz(h)ome, Radical Translocal, Post Exodus, and Demos 42 Ubuntunse were the embodiment of unknowable futures brought to life in the present, depicting an imaginary southern Africa way beyond our ambient, generic futures, yet anchored in today's seeds initiatives (See Table 3 for short summaries).
Fig. 6. The Post Exodus group performing their vision of the future.

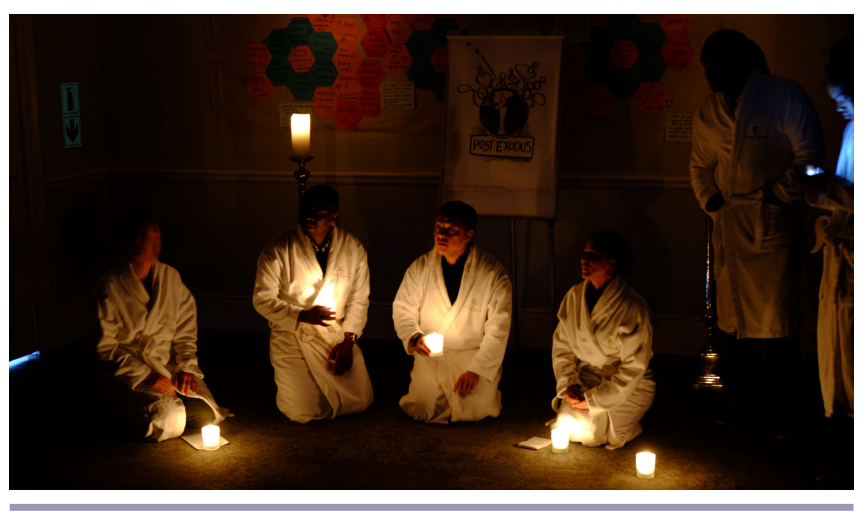

After sharing their scenarios, participants gathered in a facilitated plenary session to compare and contrast their visions, as well as deliberate the transition space between the present and the different futures. Finally, the applicability and usefulness of these kinds of creative visioning processes was explored, and future avenues of engagement were brainstormed.

\section{INSIGHTS: USING FUTURES METHODS TO FACILITATE TRANSFORMATIVE SPACES}

I do not believe Ngugi set out to write a fantastical novel. I don't think it even crossed his mind. I think he set out to write a book about Africa and in writing about Africa the magic naturally, organically sprouted (Okorafor 2009:284, on Ngũgĩ wa Thiong'o's novel Wizard of the Crow).

Reflecting on the quote by Okorafor above, the same can arguably be said about the final outcome of the SOGA visioning workshop. The convening team designed an experimental process for facilitating a group of diverse stakeholders to create radical new future visions for the southern African region in the Anthropocene. The narratives that emerged were powerful and engaging, and many participants found the process inspiring. The scenarios reflected the emergent result of an intuitive mixture of deep thinking, provocations between diverse group members, and creative imagination. Although the storylines themselves are important for further engagement around sustainability transformations in the region, the facilitation process was central to using the scenario development exercise to create a transformative space.

Three key learnings arose from using the Mānoa mash-up method as a tool for facilitating spaces for transformative change: the importance of the imagination for transformative thinking, the need to capitalize on diversity to push boundaries, and finally, the importance of creating a space that enables participants to come to terms with complexity by engaging with their emotions and beliefs through storytelling. In this section we draw on quotes from the participants as captured in the "Anthropod" to elaborate on their experience of the workshop process.

Inclusion of the arts for capturing the imagination

A key theme that emerged from the reflections of the participants, was the role that the arts could play in fostering and triggering 
Table 3. Summary of the four scenarios

\begin{tabular}{ll}
\hline \hline Name of Scenario & Brief Description \\
\hline Rhiz(h)ome & The Rhiz(h)ome world is a citizen-led, decentralized, but highly interconnected world, sustained by an empathetic,
\end{tabular}
knowledgeable, and empowered citizenry. Land ownership has been fundamentally reimagined as stewardship. The alienating notion of labor has been replaced by an emphasis on societal contribution and opportunities for selffulfilment, expression, and innovation. Technology has enabled high levels of direct participation in decision making at multiple scales. This allows communities and economies to be local and deeply context sensitive, and at the same time global and richly interconnected.

There has been a rise in new ecologically informed governance units such as bioregions as well as virtual communities. Cities are green; environmentally sensitive building technology is integrated with large, diverse urban green spaces. Highly interconnected smaller cities have replaced the development of further mega-cities, and the distinction between rural and urban is increasingly blurred. Technology has greatly increased the local production of environmentally friendly, multipurpose goods, drastically reducing transportation and waste. The economy has become process and service-based, rather than output-based. The Rhiz(h)ome world is fundamentally marked by a commitment to participation, fairness, and justice. Difference is valued and respected, and there is formal recourse for marginalized voices and perspectives. There is an openness, awareness, and curiosity about the wider world and human nature.

Radical Translocal This world is defined by equality where all opinions matter and where diverse skills are recognized. The Earth is seen as our mother: She is what nurtures, heals, provides, and supports the community. She keeps everyone in check by only giving what is needed, where it is needed. Urban learning initiatives were catalyzed by community-based natural resource management forums. This resulted in stakeholder-based property rights, which increased community buy-in and investments in local assets and ecosystem services, as well as ethical modes of production and consumption. It also led to a reduction of economic migration and allowed people to move between rural villages and cities because they chose to, not because they were forced to. Indigenous knowledge systems are cherished as a source of connectedness to nature and each other.

What started as a community meeting under a tree eventually became an ecocentric community-led movement that embraces social and environmental issues equally. Going back to the roots of humanity was a simple yet radical notion that captured the hearts of all across the globe. Technology facilitated the movement by freeing people from the offices, workstations, and mundane jobs. Most importantly, technological advancements in food production meant that everyone had enough food to eat without having to work too hard for it. Techno-food and the iMeat3000 processor changed the way the world interacted with nature very much the same way that the smartphone of the 21st century changed the way humans communicated. Finally, VERITAS, the Virtual Ecocentric Redistributive Index Tax Adaptive System, is an artificial intelligence that accounts for the full ecological cost of all the products individuals use every day and encourages sustainable behavior.

Post Exodus This scenario is set in the Year 2318, the Post Exodus era. Part of the world's population has fled the Earth, leaving behind an overexploited and degraded planet. People in southern Africa reside in thousands of small, distributed, local communities (rather than large cities) and focus on building localized, closed-loop production and consumption systems where there is no waste, resulting in thriving, enterprising village ecosystems with strong African identities. The advancements in technology allow for these village ecosystems to be digitally connected to each other across the globe, forming truly "glocal" communities.

People meet, interact, and share knowledge and experiences in "The Collective," a physical and virtual community space, where cultural and artistic self-expression is highly valued. At the core of the Collective is building the understanding between people, cultures, and contexts, to encourage empathy and humility. Advanced gene therapy has resulted in the eradication of disease and very long, healthy life spans. Decisions are made with the help of situational leaders, through a system of deep dialogue. A newly developed, globally shared language allows for this engagement between communities, while local languages and cultures are actively maintained. As a whole, society is slowly moving toward a collective consciousness, brought about by extensive knowledge sharing and a profound commitment to this world's principal and most revered value: empathy. Demos42 Ubuntunse $\quad \begin{aligned} & \text { Demos42 is the collective super intelligence that connects and guides humanity, based on the principle of Ubuntunse. S } \\ & \text { (h)e emerged as the antidote to false data by using collective thinking to create a nurturing super-intelligence on which }\end{aligned}$ the vision of society is founded. Out of Demos 42 an era of radical transparency emerged; the line between leaders and followers no longer exists. Power and expertise are diffused and because of Demos42's demilitarization process, there are no longer borders: no nation states and no passports and therefore no hierarchical governance system. Infrastructure is fluid; with the advent of AI and "4D printing," intelligent self-energizing blocks construct themselves into built forms as needed, e.g., as an office building during office hours, and then a sports stadium just for that evening's game. This multipurpose usefulness frees up much needed space for other activities, especially communal uses such as renewable energy generation and water catchment.

Food is the catalyst for changing social relations through the concept of a "slow-food" nostalgic future that is progressive, but recognizes the knowledge of the past. Everywhere are 3-D vertical and horizontal gastrogardens from which the community gathers free edible plants and insects. Living spaces are alive and gastronomic knowledge is available to everyone who now has the time to use their skills, freed from the drudgery of the everyday, now undertaken by shapeshifting, intelligent infrastructure. 
transformations in social-ecological systems. In the Radical TransLocal group's scenario, a deep engagement with the arts was the trigger for a move from a dystopian society to an eventual good Anthropocene. But, beyond the importance of art in the scenario storylines, it played a pivotal role in the process of creating the scenarios, truly envisioning the future, and relating those visions to the other participants. We found that including artists was a simple, yet effective way to connect participants to their creative side and played an important role in facilitating a "transformative space." The fact that the scenarios were mostly unconstrained, apart from the instruction to focus on developing a positive vision for southern Africa, further allowed for creativity.

It was interesting because it created a playful environment... to create an environment where there is no judgement, where there is freedom...

A sense of inventiveness, of imaginativeness, freedom and agency, those are on the rise... so the kind of work that we're doing here [is] to strengthen and invigorate our own imaginative capacities and to understand maybe some of the connections between these imagined futures and what we do today...

The introductory PRACTIS session on art, imagination, and futures at the beginning of the workshop set the tone for a relaxed, informal process in which participants could feel safe and that allowed them to be more open-minded and to engage in the process more creatively. One participant explained it as follows:

The most valuable part of this whole process, I think was already indicated when we had our introductory session ... when we arrived. And this was really the idea of freeing our imagination of what simply was available to us at this moment in time. And I think it is really critical that we remember that the output, the futures that we designed are still actually present futures because even if we didn't imagine them at the beginning of this process, we have now added them, and so they have become in a sense part of the world that we are tangibly engaging with.

Presenting the scenarios as minitheatrical performances contributed to the experience of the future that was being created before the participants' eyes. It had a powerful effect, as this participant explains:

The performative element, that was in each of the ways the groups presented the scenarios, was super powerful. It really was a distillation, extrapolation, and creative reworking of those three seeds we started with.

One of the things that was really remarkable for me was the depth actually of that multidimensionality and the performance today. It felt like the facilitators were helping us feel our way into the visions of the good Anthropocene that people were trying to express. And they did.

The SOGA visioning process enabled a spirit of imagination to stimulate creative thinking for addressing sustainability issues and enabling transformations (see Bendor et al. 2017). It furnished participants with the capacities needed to envision and engage experientially with major shifts that may be required for responding to the challenges associated with the Anthropocene and what impacts these shifts could have on our ways of being.

\section{Capitalizing on diversity to push boundaries}

The diversity within the composition of the participant group also contributed significantly to the process. This diversity was apparent on many levels, from the participants' areas of expertise and backgrounds to their assumptions and ideas about what was "good" or "bad." Key to navigating this diversity was the creation of an enabling space within which the participants could interactively engage with radically alternative futures from different perspectives. As this participant points out, the diversity among the participants added complexity to the process, and posed some challenges, not so much during big-picture visioning, but in fleshing out the details of the transformation to a good Anthropocene:

One of the nice things was that we didn't know each
other... there was a mystery element and we didn't know
how this will proceed. ... But when it comes to fleshing
things out and putting much more detail onto it, that's
where you get into a lot of more difficult issues. When
people's lived experiences, professional lives, when things
they thought and the values they hold all come together,
it can become a set of challenges, but again, we managed
to find a way through this and gradually started to build
up this idea.

This diversity of ideas and perspectives also meant that the workshop was, at times, challenging. Differences in underlying values, assumptions, and stereotypes required participants to not only engage intellectually but also emotionally. Most participants reflected deeply about their emotional connections to the environment and focused a lot on morals and ethics of the alternative futures they were cocreating.

It's been hard work. Emotionally difficult work. To think
into the future and in that process to kind of really try
very hard to let go of some of your pet ideas, things that
make you feel comfortable. Some of your unquestioned
ways of engaging with the world.

There was a realization that there were many different ideas of what a good Anthropocene could look like and how it might be achieved. The experiences of the seed representatives enriched the stories, in addition to the details added by the scientists and artists.
It's tricky, but important to get in spaces with multiple kinds of minds and multiple experiences and to put yourself into that, but then to release and let go and watch the group work their way around it because there's certainly not one or 10 or a hundred people building the good Anthropocene, it's millions and millions...

Having to negotiate different ideas within the groups resulted in rich discussions that required a space that encouraged trust between the participants. The introductory PRACTIS session set up a feeling of openness and trust between the participants, most of whom had never met before, that continued through the group work. Even when two participants chose to switch groups, there was no animosity between the group members, and a feeling of amity developed between the participants, aided by important informal interactions during lunches and dinners. 
I think in the end the final product really represented something of all of us and again I think that sometimes that's not always the case. Quite often when you do these processes, it becomes very dominated by one or two people and I didn't feel that was the case so everyone was excited about it because we all had ownership and I think that's down to the way the process was designed.

I absolutely love the group that I'm in, we really gel, we work easily together and we've brought out very good sides to each other... and so we've managed to deal with the lack of certainty in a very constructive way and I think that's a credit to the process...

In setting out to create and facilitate a space that has the potential to be transformative, enabling diverse perspectives to come together is a tricky, but critical part of the facilitation. Processes that help participants reflect on their assumptions, and that build trust and openness are key.

Understanding complexity by engaging with emotions and beliefs Designing the facilitation process in a way that engaged participants' emotions, and challenged their beliefs, was central to the creation of a transformative space. The workshop allowed for reflection and learning, assisted by a number of specific interventions: First, upon arrival at the workshop the participants were handed booklets and were encouraged to make notes of their learnings and reflections. The Anthropod was another intervention meant to encourage participants to reflect deeply on the thoughts and feelings during the workshop.

It was beneficial to the learning process that the program allowed for sufficient and ample time to engage with each other. Sessions were not rushed, and group work time was generously allocated. In addition, the workshop was held in a comfortable physical space with sufficient break-out rooms and privacy. The workshop was designed so that the same people remained together in a group throughout the whole process, with some flexibility in terms of moving one or two people into different groups when dynamics required this. This helped the scenarios take on the groups' identities and fostered a team spirit within the groups.

This environment is so important, there is something zenlike and calming which allows you to step comfortably into the future... and indeed one of the hardest things has been bringing ourselves back.

Sufficient time and space allowed participants to contemplate, both individually and collectively, the process and the content of the scenarios that were cocreated, how their visions of the future connected to the present, and how their insights could be incorporated in the everyday work they do themselves. This included extending the process to work with marginalized groups in local languages and a subsequent collaboration with one of the participants has resulted in a training workshop in broader futures methods, including the Mānoa mash-up, for use in diverse development environments.

Coming from a development perspective, it became evident to me that this was a necessary research tool for underprivileged communities in particular, as it holds the promise of expanding on existing participatory methods. Rather than simply describing their realities, a well- designed method would enable them to do something they are seldom trusted with: craft a detailed picture of their futures and take full ownership of it. In this, lies the potential for a small but important revolution in development...

One of the main challenges that participants had to grapple with was the paradoxes and contradictions amongst the seeds they were allocated, and within the scenarios that emerged from each group. Paradoxes and contradictions exist in the present all around us, and they will also exist in the future, but it requires acceptance of this fact to move beyond some of the major sticking points in the scenario development process. Yet it is these points of contention at which key breakthroughs in understanding often occurred within groups. These contractions personally challenged people to confront their underlying assumptions and beliefs:

When scenarios were articulated, and we got the thinking going, the challenges, and we got the exploring, we got the visioning, revisioning and thinking of what we understand as daily issues, I was excited, but at [the same] time I was afraid, because it then challenged my daily thinking, and how to act in my daily role in working in a multilateral entity.

Some participants found the process to be personally transformative in that they started to believe very strongly in their cocreated alternative vision of the future. One person expressed that the exercise had transformed the way she felt about and envisioned the future, and that it filled her with a sense of hope but also a sense of responsibility, to encourage the initiatives and ideas that could help lead to this bright future.

We believed the things we have somehow constructed.
That for me increasingly made it transformative. I am
curious to see how I really take this into my life, but now
that I feel and believe this about the world, I have a
responsibility to act in a certain way. To either advance
the things that are worthy ... going into the future and
disrupt the things that are not. By definition, we do these
things in a certain sense in our day to day lives, but this
is a far more visionary understanding of the world and a
far more bolder and richer form with fundamental
transformative implications.

Grappling with envisioning more positive futures and being able to link them to current practices was a powerful process for many of the participants. Using the future to think about how to navigate transformation to a more sustainable world and being able to link these visions to present actions through the construction of narratives lay at the core of the facilitation of this process. Being able to provide an approach whereby people can engage with the complexity of transformation processes, work with it, and link it to how they engage with the world in the present underpinned the success of the workshop.

\section{Limitations}

It is important to recognize that, as with all methods, there are limitations to the Mānoa mash-up. First, it is a very time intensive process and this can often limit the participation of some people unless they see a direct benefit for their work. Convening participants is also limited to the networks of the convenors and so, despite all efforts to engage broadly and with diverse groups of people, there will always be constraints as to who is willing and 
able to attend such a workshop. The choice of the seed initiatives used in the process was also based on extensive discussion within the convening team, and constrained by which initiatives we were able to represent in the workshop itself. Starting from different seed initiatives would have resulted in different visions. The process is therefore highly dependent on who is invited to participate and what seed initiatives are chosen for the process. Finally, this was an experimental process that was being piloted. Subsequent uses of the approach (including letting participants choose their own seed initiatives) have adapted it to meet the needs of the organizers and participants; it is vital to remember that the process should always be designed to meet specific needs and objectives and so this method will only be useful in specific circumstances when creative, more radical future visions are required.

\section{CONCLUSION}

Cocreating novel futures together in a world defined by complexity, diversity, and uncertainty calls for creative, collaborative, and experimental tools and methods that create spaces for transformative understanding and action. A sensitivity to the inherent complexity that characterizes the world has implications for how we develop models for understanding the self-organizing relations and complex causal and adaptive dynamics of the future (Levin et al. 2013). Because we cannot calculate nonprobabilistic futures, we are challenged to employ our creative capacities to envision radically different futures with novel methods that can capture and embrace the fundamental uncertainties and conflicting values of a changing world.

This paper has documented an innovative process that attempted to engage with the complexity of the future Anthropocene and the many challenges it poses. The Mānoa mash-up process that we designed for imagining radically alternative futures opened up a transformative space for change, drawing on the power of collective visioning and storytelling. The key aspects of the process that made this possible were (1) inspiring the imagination by incorporating the arts and artists, (2) including a wide diversity of participants, and (3) engaging participants' emotions and challenging their beliefs to find a way to accept complexity and apply this learning in their own lives.

An important consideration is how this method and the narratives that it produced are taken up and used by the participants and the broader community. The discussion and reflection session on the final day of the SOGA workshop highlighted how the participants were planning to use the outcomes of the workshop in their own work. These included using the narratives as talking points at Africa-wide events like those convened by UN bodies, and employing the method with local communities to capture future visions from people whose voices are often marginalized in environmental scenario processes. It was also suggested that artworks depicting the visions be commissioned and that African writers be asked to write short stories based on these futures for wider dissemination (for example, Merrie et al. 2017). Furthermore, the Mānoa mash-up method has subsequently been employed and adapted in two further workshops: (1) to develop visions of a good Anthropocene for northern Europe, with a similar set of people convened in Sweden, and (2) an international group of stakeholders, including activists and politicians, in New Zealand under the auspices of the Intergovernmental Panel on
Biodiversity and Ecosystem Services to discuss "Nature Futures" (Pereira et al. 2017, Rosa et al. 2017).

The Mānoa mash-up method provides a novel approach to thinking about radical far futures. It makes an important contribution to the recent developments by the futures community to create tools and approaches that are more relevant for decision making under conditions of complexity. More broadly, the method contributes to a growing set of approaches to help societies grapple with the systemic changes that are required to prosper in a good Anthropocene (see Preiser et al. 2017). Rather than advocating for a universal approach, this method hopes to engage with context specific and diverse understandings of what constitutes a desirable future. This engagement with narratives of the future is a critical aspect in the creation of transformative spaces. It is hoped that by injecting a method that actively works with diversity, complexity, and imagination in tackling these challenges, there will be more positive stories around the world that galvanize action for a more sustainable future.

Responses to this article can be read online at: http://www.ecologyandsociety.org/issues/responses. $\mathrm{php} / 9907$

\section{Acknowledgments:}

We would like to thank the incredible visioning workshop participants for their enthusiasm and willingness to throw themselves into this process. Without you nothing would have been possible. We would also like to show our gratitude to the great comms team who captured so much of the material that we have used in this paper on film and photo. Comments from two anonymous reviewers also helped us to strengthen our argument and we extend our thanks to them. This paper has been produced as part of the Guidance for Resilience in the Anthropocene: Investments for Development (GRAID) Programme led by the Stockholm Resilience Centre at Stockholm University, and funded by the Swedish Development Cooperation Agency (Sida).

\section{LITERATURE CITED}

Arthur, W. B. 2011. The nature of technology: what it is and how it evolves. Free Press, New York, New York, USA.

Bai, X., S. van der Leeuw, K. O’Brien, F. Berkhout, F. Biermann, E. S. Brondizio, C. Cudennec, J. Dearing, A. Duraiappah, M. Glaser, A. Revkin, W. Steffen, and J. Syvitski. 2016. Plausible and desirable futures in the Anthropocene: a new research agenda. Global Environmental Change 39:351-362. http://dx.doi. org/10.1016/j.gloenvcha.2015.09.017

Barnosky, A. D., E. A. Hadly, J. Bascompte, E. L. Berlow, J. H. Brown, M. Fortelius, W. M. Getz, J. Harte, A. Hastings, P. A. Marquet, N. D. Martinez, A. Mooers, P. Roopnarine, G. Vermeij, J. W. Williams, R. Gillespie, J. Kitzes, C. Marshall, N. Matzke, D. P. Mindell, E. Revilla, and A. B. Smith. 2012. Approaching a state shift in Earth's biosphere. Nature 486:52-58. http://dx.doi. org/10.1038/nature11018 
Bendor, R., D. Maggs, R. Peake, J. Robinson, and S. Williams. 2017. The imaginary worlds of sustainability: observations from an interactive art installation. Ecology and Society 22(2):17. http:// dx.doi.org/10.5751/ES-09240-220217

Bennett, E. M., M. Solan, R. Biggs, T. McPhearson, A. V. Norström, P. Olsson, L. Pereira, G. D. Peterson, C. RaudseppHearne, F. Biermann, et al. 2016. Bright spots: seeds of a good Anthropocene. Frontiers in Ecology and the Environment 14 (8):441-448. http://dx.doi.org/10.1002/fee.1309

Biggs, R., F. R. Westley, S. R. Carpenter, J. Lorimer, W. Steffen, W. Broadgate, L. Deutsch, O. Gaffney, C. Ludwig, Å. Persson, L. Deutsch, J. Zalasiewicz, M. Williams, K. Richardson, C. Crumley, P. J. Crutzen, C. Folke, L. Gordon, M. Molina, V. Ramanathan, J. Rockström, M. Scheffer, H. Schellnhuber, U. Svedin, F. Jaramillo, G. Destouni, and F. Berkhout. 2015. The Anthropocene: from global change to planetary stewardship. Anthropocene Review 40(2):739-761.

Bishop, P., A. Hines, and T. Collins. 2007. The current state of scenario development: an overview of techniques. Foresight 9 (1):5-25. http://dx.doi.org/10.1108/14636680710727516

Bland, J., and S. Westlake. 2013. Don't stop thinking about tomorrow: a modest defence of futurology the role of complaints in transforming public services. Nesta, London, UK.

Candy, S., and J. Dunagan. 2017. Designing an experiential scenario: the people who vanished. Futures 86:136-153. http://dx. doi.org/10.1016/j.futures.2016.05.006

Crutzen, P. J. 2002. Geology of mankind. Nature 415:23. http:// dx.doi.org/10.1038/415023a

Curry, A. 2015. Searching for systems: understanding Three Horizons. APF Compass January:11-13.

Dator, J. 2009. Alternative futures at the Manoa School. Journal of Futures Studies 14(2):1-18.

Evans, A. 2017. The myth gap. Penguin Random House, London, UK.

Geels, F. W. 2002. Technological transitions as evolutionary reconfiguration processes: a multi-level perspective and a casestudy. Research Policy 31:1257-1274. http://dx.doi.org/10.1016/ $\underline{\mathrm{S} 0048-7333(02) 00062-8}$

Glenn, J. C. 2009. The futures wheel. Pages 1-17in J. C. Glenn and T. J. Gordon, editors. Futures research methodology. Millennium Project, Washington D.C., USA.

Harari, Y. N. 2016. Homo Deus: a brief history of tomorrow. Harvill Secker, London, UK.

Hunt, D. V. L., D. R. Lombardi, S. Atkinson, A. R. G. Barber, M. Barnes, C. T. Boyko, J. Brown, J. Bryson, D. Butler, S. Caputo, et al. 2012. Scenario archetypes: converging rather than diverging themes. Sustainability 4(4):740-772. http://dx.doi.org/10.3390/ $\underline{\mathrm{su} 4040740}$

Levin, S., T. Xepapadeas, A.-S. Crépin, J. Norberg, A. de Zeeuw, C. Folke, T. Hughes, K. Arrow, S. Barrett, G. Daily, P. Ehrlich, N. Kautsky, K.-G. Mäler, S. Polasky, M. Troell, J. R. Vincent, and B. Walker. 2013. Social-ecological systems as complex adaptive systems: modeling and policy implications. Environment and
Development Economics 18(2):111-132. http://dx.doi.org/10.1017/ $\underline{\mathrm{S} 1355770 \mathrm{X} 12000460}$

Lum, R. 2015. Working with Verge. APF Compass April:5-8.

McPhearson, T., D. M. Iwaniec, and X. Bai. 2016. Positive visions for guiding urban transformations toward sustainable futures. Current Opinion in Environmental Sustainability 22:33-40. http:// dx.doi.org/10.1016/j.cosust.2017.04.004

Merrie, A., P. Keys, M. Metian, and H. Österblom. 2017. Radical ocean futures-scenario development using science fiction prototyping. Futures. http://dx.doi.org/10.1016/j.futures.2017.09.005

Milkoreit, M. 2016. The promise of climate fiction: imagination, storytelling, and the politics of the future. Pages 171-191 in P. Wapner and $\mathrm{H}$. Elver, editors. Reimagining climate change. Routledge, Oxford, UK.

Millennium Ecosystem Assessment. 2005. Ecosystems and human well-being: synthesis. Island Press, Washington, D.C., USA.

Miller, R. 2013. Changing the conditions of change by learning to use the future differently. Pages 107-111 in World Social Science Report. OECD and UNESCO Publishing, Paris, France. http:// dx.doi.org/10.1787/9789264203419-14-en

Miller, R., R. Poli, and P. Rossel. 2013. The discipline of anticipation: exploring key issues. Scoping Global/Local Anticipatory Capacities Working Paper 1. UNESCO, Paris, France.

Moore, M.-L., O. Tjornbo, E. Enfors, C. Knapp, J. Hodbod, J. A. Baggio, A. Norström, P. Olsson, and D. Biggs. 2014. Studying the complexity of change: toward an analytical framework for understanding deliberate social-ecological transformations. Ecology and Society 19(4):54. http://dx.doi.org/10.5751/ ES-06966-190454

Nye, D. E. 2014. The United States and alternative energies since 1980: technological fix or regime change? Theory, Culture \& Society 31(5):103-125. http://dx.doi.org/10.1177/0263276414537314

Okorafor, N. 2009. Organic fantasy. African Identities 7 (2):275-286. http://dx.doi.org/10.1080/14725840902808967

Okri, B. 2015. Mystery feast: thoughts on storytelling. Clairview Books, West Hoathly, UK.

Olsson, P., L. H. Gunderson, S. R. Carpenter, P. Ryan, L. Lebel, C. Folke, and C. S. Holling. 2006. Shooting the rapids: navigating transitions to adaptive governance of social-ecological systems. Ecology and Society 11(1):18. http://dx.doi.org/10.5751/ ES-01595-110118

Pereira, H., R. Alkemade, E. Den Belder, S. C. Ribeira, K. Davies, A. Greenaway, H. Kim, N. King, T. Lazarova, L. Pereira, G. Peterson, F. Ravera, A. Argumedo, C. Arida, D. Armenteras, A. G. Ausseil, B. Baptiste, J. Belanger, K. Bingham, J. Carino, P. A. Van Damme, R. Devivo, F. Dickson, J. P. Dushimumuremyi, S. Ferrier, J. G. Marquez, S. Greenhaigh, D. J. Hamilton, P. Hardison, G. Hicks, K. Hughey, M. De Kock, P. Leadley, F. Lemaitre, E. Maltseva, C. D. M. Scaramuzza, M. Metwally, W. Nelson, H. Ngo, C. Neumann, C. Norrie, J. Perry, R. Quintana, V. E. R. Osuna, C. Roehrl, J. Seager, H. Sharpe, T. Shortland, P. Shulbaeva, R. Sumaila, T. Takahashi, N. Titeux, S. Tiwari, C. 
Trisos, A. Wheatley, D. Wilson, S. Wood, E. Van Wyk, T. X. Yue, D. Zulfikar, M. Brake, and D. Leigh. 2017. New visions for nature and nature's contributions to people for the 21st century. Intergovernmental Panel on Biodiversity and Ecosystem Services (IPBES) secretariat, Bonn, Germany.

Pereira, L. M., E. M. Bennett, R. O. Biggs, G. D. Peterson, T. McPhearson, A. V. Norström, P. Olsson, R. Preiser, C. RaudseppHearne, and J. M. Vervoort. 2018. Seeds of the future in the present: exploring pathways for navigating towards "Good Anthropocenes." In T. Elmqvist, X. Bai, N. Frantzeskaki, C. Griffith, D. Maddox, T. McPhearson, S. Parnell, P. Romero Lankao, D. Simon, and M. Watkins, editors. Urban planet: knowledge towards sustainable cities. Cambridge University Press, Cambridge, UK, in press.

Polanyi, K. 1944. The great transformation: the political and economic origins of our time. Beacon, Boston, Massachusetts, USA.

Poli, R. 2015a. The implicit future orientation of the capability approach. Futures 71:105-113. http://dx.doi.org/10.1016/j. futures.2015.03.002

Poli, R. 2015b. Social foresight. On the Horizon 23(2):85-99. http:// dx.doi.org/10.1108/OTH-01-2015-0003

Preiser, R., L. M. Pereira, and R. Biggs. 2017. Navigating alternative framings of human-environment interactions: variations on the theme of 'Finding Nemo.' Anthropocene 20:83-87. http://dx.doi.org/10.1016/j.ancene.2017.10.003

Rosa, I. M. D., H. M. Pereira, S. Ferrier, R. Alkemade, L. A. Acosta, H. R. Akcakaya, E. den Belder, A. M. Fazel, S. Fujimori, M. Harfoot, et al. 2017. Multiscale scenarios for nature futures. Nature Ecology and Evolution 1:1416-1419. http://dx.doi. org/10.1038/s41559-017-0273-9

Sardar, Z., and J. A. Sweeney. 2016. The three tomorrows of postnormal times. Futures 75:1-13. http://dx.doi.org/10.1016/j. futures.2015.10.004

Schultz, W. 2015. Manoa: the future is not binary. APF Compass April:22-26.

Sharpe, B., A. Hodgson, G. Leicester, A. Lyon, and I. Fazey. 2016. Three horizons: a pathways practice for transformation. Ecology and Society 21(2):47. http://dx.doi.org/10.5751/ES-08388-210247

Sornette, D., and P. Cauwels. 2015. Managing risk in a creepy world. Journal of Risk Management in Financial Institutions 8 (1):83-108.

Steffen, W., W. Broadgate, L. Deutsch, O. Gaffney, and C. Ludwig. 2015. The trajectory of the Anthropocene: the great acceleration. Anthropocene Review 2(1):81-98. http://dx.doi.org/10.1177/2053$\underline{019614564785}$

United Nations. 2015. Transforming our world: the 2030 agenda for sustainable development. UN, New York, New York, USA.

Urry, J. 2016. What is the future? Polity, Cambridge UK.

van der Helm, R. 2009. The vision phenomenon: towards a theoretical underpinning of visions of the future and the process of envisioning. Futures 41(2):96-104. http://dx.doi.org/10.1016/j. futures.2008.07.036
Wiek, A., and D. Iwaniec. 2014. Quality criteria for visions and visioning in sustainability science. Sustainability Science 9 (4):497-512. http://dx.doi.org/10.1007/s11625-013-0208-6 